$16^{\text {th }}$ International Conference on

AEROSPACE SCIENCES \& AVIATION TECHNOLOGY,

$\boldsymbol{A S A T}$ - 16 - May 26 - 28, 2015, E-Mail: asat@mtc.edu.eg

Military Technical College, Kobry Elkobbah, Cairo, Egypt

Tel : +(202) 24025292 - 24036138, Fax: +(202) 22621908

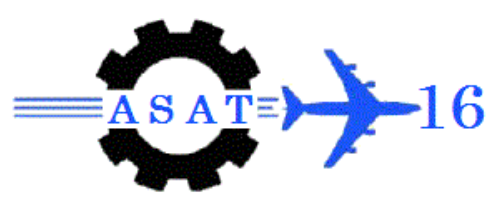

\title{
PERFORMANCE INVESTIGATION OF AXIAL PISTON PUMPS OF CONSTANT POWER REGULATION
}

\author{
M. Semeda*, M. Galal Rabie ${ }^{* *}$, A. Sabry ${ }^{* * *}$
}

\begin{abstract}
The industrial variable displacement of axial piston pump conical cylinder has wide application in hydraulic drives of mobile machinery in view of some advantages, such as good features good suction characteristics, low noise level,small dimensions and weight at high values of working pressure. Also good solutions in presses, milling production line machine, stucker in cement production line. Our pump with constant power regulator has many applications but is a good solution in deep drawing presses used in home appliance industry very spreader in Egypt .I replaced an old line of pumps. So the study of this pump with specified control is essential to develop a model validated. This paper is dedicated to investigate the steady state and dynamic performance of this class. The pump controller is of rocker-arm type, it serves to produce constant output hydraulic power. The study includes the development of non-linear mathematical model of the pumping mechanism and the pump controller. The mathematical models were used to develop computer simulation programs by using Simulink-matlab program. The study included an experimental part where the steady state and transient responses were measured. An acceptable agreement between the simulation and experimental results was observed, which validates the developed simulated model program. The simulation model program was used to conduct a parametric study. The results are presented and analyzed.
\end{abstract}

\section{KEY WORDS}

Axial, piston, pump, hydraulic, constant power, conical cylinder block, inclined pistons, a4vso, control.

\section{NOMENCLATURE}

$\gamma \quad$ Rocker arm rotational angle, rad

$\mathrm{A}_{\mathrm{co}} \quad$ Area of cut-off valve spool, $\mathrm{m}^{2}$

$\mathrm{A}_{\mathrm{cod}} \quad$ Area of the cut-off valve damping orifice, $\mathrm{m}^{2}$

$\mathrm{A}_{\mathrm{coi}} \quad$ Throttling area for the flow inlet to the cut-off valve, $\mathrm{m}^{2}$

$\mathrm{A}_{\text {coo }} \quad$ Throttling area for the flow outlet from the cut-off valve reducer, $\mathrm{m}^{2}$

$\mathrm{A}_{\mathrm{d}}, \mathrm{A}_{\mathrm{s}} \quad$ Post plate delivery and suction areas, $\mathrm{m}^{2}$

$\mathrm{a}_{\mathrm{k}} \quad$ Acceleration of the kth piston, $\mathrm{m} / \mathrm{s}^{2}$

$\mathrm{A}_{\mathrm{opl}} \quad$ Area of the servo-piston damping orifice, $\mathrm{m} 2$

Aopl Area of the servo-piston damping orifice, $\mathrm{m} 2$

Ap servo piston right area, subjected to pump exit pressure, $\mathrm{m} 2$

Apl Plunger area, $\mathrm{m} 2$

Apri Throttling area for the flow inlet to the pressure reducer, $\mathrm{m} 2$

Apro Throttling area for the flow outlet from the pressure reducer, m2

\footnotetext{
* $\quad$ MSc Eng., Technical office manager YFHE Bosch Rexroth, Egypt.

** Professor, Modern Academy for Engineering and Technology, Cairo

*** Professor, Faculty of Engineering, Cairo University
} 



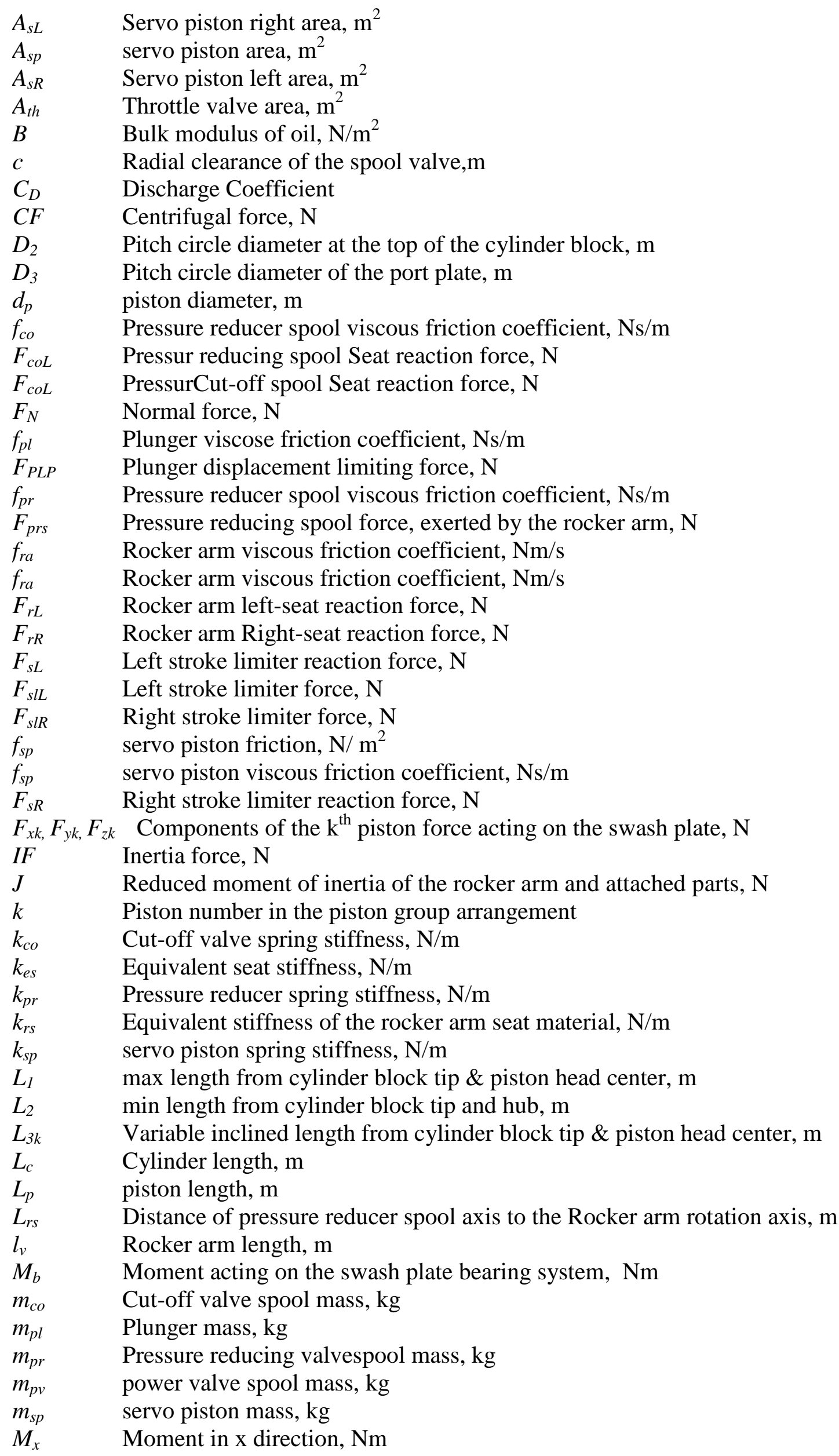


$M_{y} \quad$ Moment in y direction, $\mathrm{Nm}$

$\mathrm{Mz} \quad$ Moment in $\mathrm{z}$ direction, $\mathrm{Nm}$

$n \quad$ Pump speed, rps

$P \quad$ Value of the controlled constant power, W

$P_{C C} \quad$ Pressure at which control (commencement) start working, $\mathrm{Pa}$

$P_{c k} \quad$ Piston chamber pressure, $\mathrm{Pa}$

$P_{c o} \quad$ Pressure in the cut-off valve left chamber, $\mathrm{Pa}$

$P_{c o} \quad$ Pressure in the cut-off calve left chamber, $\mathrm{Pa}$

$p_{\max } \quad$ Static characteristic maximum pressure, $\mathrm{Pa}$

$P_{p} \quad$ pump delivery pressue, $\mathrm{Pa}$

$P_{p l} \quad$ Pressure in the plunger chamber, $\mathrm{Pa}$

$P_{p r} \quad$ Reduced pressure, $\mathrm{Pa}$

$p_{s} \quad$ Pump suction pressure, $\mathrm{Pa}$

$P_{s p} \quad$ Servo piston pressure, $\mathrm{Pa}$

$P_{s p} \quad$ sevo piston pressure, $\mathrm{Pa}$

$P_{t} \quad$ Return line pressure, $\mathrm{Pa}$

$Q_{c o} \quad$ Flow rate through the cut-of valve damping orifice, $\mathrm{m}^{3} / \mathrm{s}$

$Q_{c o i} \quad$ Flow rate inlet from reduced pressure chamber to servo-piston chamber, $\mathrm{m}^{3} / \mathrm{s}$

$Q_{\text {coo }} \quad$ Flow rate outlet from Cut-off valve to servo-piston chamber, m3/s

$Q_{d} \quad$ Delivery flow rate of one cylinder, $\mathrm{m}^{3} / \mathrm{s}$

$Q_{\max } \quad$ Static characteristic maximum flow rate, $\mathrm{m}^{3} / \mathrm{s}$

$Q_{p l} \quad$ Flow rate through the servopiston damping orifice, $\mathrm{m}^{3} / \mathrm{s}$

$Q_{p r} \quad$ Flow rate from the high pressure port to the reduced pressure port, $\mathrm{m}^{3} / \mathrm{s}$

$Q_{p r i} \quad$ Flow rate inlet from the reduced pressure line to return line, $\mathrm{m}^{3} / \mathrm{s}$

$Q_{\text {pro }} \quad$ Flow rate outlet from pressure reducer to its exit line chamber, $\mathrm{m}^{3} / \mathrm{s}$

$Q_{R} \quad$ Flow rate delivered to the cut-off valve, $\mathrm{m}^{3} / \mathrm{s}$

$Q_{R T} \quad$ Flow rate from the reduced pressure port to the return line, $\mathrm{m}^{3} / \mathrm{s}$

$Q_{s} \quad$ Suction flow rate into one cylinder, $\mathrm{m}^{3} / \mathrm{s}$

$Q_{t h r} \quad$ Flow rate through the pump loading throttle valve, $\mathrm{m} 3 / \mathrm{s}$

$r$

$r_{c k} \quad$ Radius of the trace of the piston center of gravity relative to the $\mathrm{Z}$ axis, $\mathrm{m}$

$R_{e s} \quad$ Equivalent seat friction coefficient, Ns/m

$R_{L} \quad$ Pump resistance to leakage Ns/m5

$r_{p} \quad$ Piston radius, $\mathrm{m}$

$R_{S} \quad$ Radius of swash plate swinging, $\mathrm{m}$

$r_{s w} \quad$ Swash plate arm radius, $\mathrm{m}$

$t \quad$ Time, s

$T_{s p} \quad$ Swash plate moment, $\mathrm{Nm}$

$V_{\text {coo }} \quad$ Initial volume of oil in the cut-off valve chamber,m3

$V_{g} \quad$ Pump displacement, $\mathrm{m} 3 / \mathrm{rev}$

$V_{o} \quad$ Piston chamber clearance volume, $\mathrm{m} 3$

$V_{p} \quad$ Piston velocity $\mathrm{m} / \mathrm{s}$

$V_{p l o} \quad$ Initial volume of oil in the inner plunger chamber, m3

$V_{p r} \quad$ Volume of reduced pressure chamber, m3

$V_{s p} \quad$ Control volume on the two sides of the control servo piston, $\mathrm{m} 3$

$V_{s p i} \quad$ Initial volume of servo piston chamber, $\mathrm{m} 3$

$x \quad$ Height of the cleared circle segment, $m$

$X_{c o} \quad$ Cut-off valve spool displacement, $\mathrm{m}$

$x_{c o i} \quad$ Initial opening of the exit port, $\mathrm{m}$

$x_{\text {coo }} \quad$ Initial compression of pressure reducer spring, $\mathrm{m}$

$x_{k}, y_{k}, z_{k}$ Coordinates of piston spherical head center relative to the inertial frame of reference, $\mathrm{m}$ 


$\begin{array}{ll}x_{p l} & \text { Plunger displacement, } \mathrm{m} \\ x_{p l L} & \text { Plunger displacement limit, } \mathrm{m} \\ x_{p r} & \text { Pressure reducer spool diaplacement, } \mathrm{m} \\ x_{p r i} & \text { Initial opening of the pressure reducer valve opening, } \mathrm{m} \\ x_{p r o} & \text { Initial compression of pressure reducer spring, } \mathrm{m} \\ y & \text { servo piston displacement, } \mathrm{m} \\ y_{m} & \text { Maximum servo-piston displacement, } \mathrm{m} \\ y_{m i} & \text { Minimum servo-piston displacement, } \mathrm{m} \\ y_{o} & \text { servo piston spring precompression, } \mathrm{m} \\ z & \text { Number of piston } \\ \alpha . & \text { Swash plate angular velocityrad/s } \\ \beta & \text { Cylinder block cone angle, rad } \\ \gamma & \text { Rocker arm rotational angle, rad } \\ \eta_{v} & \text { Volumetric efficiency. } \\ \theta_{k} & \text { Angular position of the } \mathrm{k}^{\text {th }} \text { piston, rad } \\ \theta_{o} & \text { Theta initial deg, rad } \\ \theta_{p} & \text { Angle subtended by the piston, rad } \\ \rho & \text { Oil density, kg/m2 } \\ \omega & \text { Pump angular speed,rad/s }\end{array}$

\section{INTRODUCTION}

Variable displacement displacement pumps are widly used for control or economic reasons. The constant power controllers are among the most important controllers applied for economic reasons. This class of controllers enable reducing the pump prime movers power by $50 \%$, enabling performing all of the system functions, with reduced speeds. A perfect constant power controller gives perfect constant power curve between the controle commencement power and the maximum pressure point, Fig.1. Formerly, It was not possible to produce such relation. It could be approximated by two or three ling-segments, Fig.1.

Many trials were paid to produce an idial hyperbolic $\mathrm{Q}(\mathrm{P})$ relation to improve the pump economy. The work of Gad [3] was among these trials. He investigated the static and dynamic characteristics of a bent axis piston pump, with constant power controller. He proposed a controller incorporating a hydraulic accumulator to produce the constant power relation. The accumulator replaced the spring used in the feedback path. Simulation results showed better exploitation of the available power when this type of controller is used, if the oil temperature is constant. The variation of oil temperature or leakage of charging gas will deteriorate the targeted constant power relation.

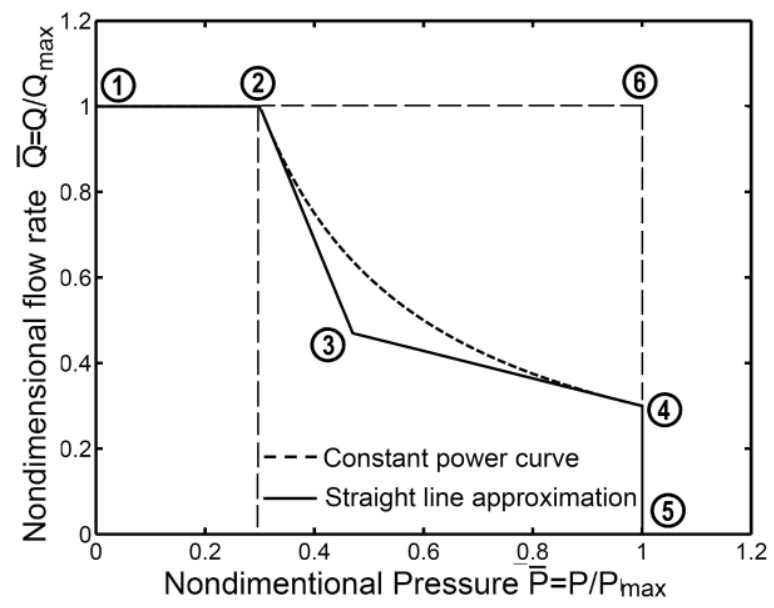

(b) Two-segments [1]

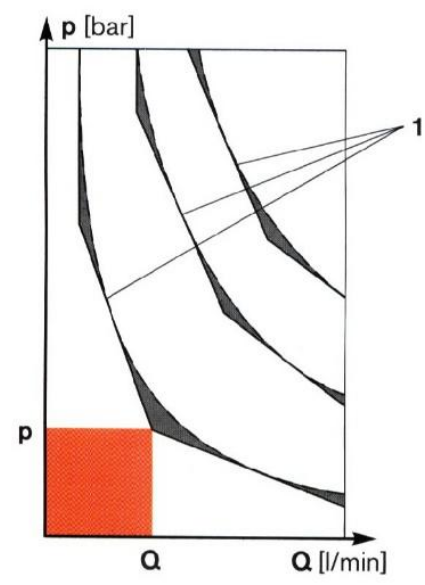

(a) Three segments [2]

Fig. 1. constant power controller 


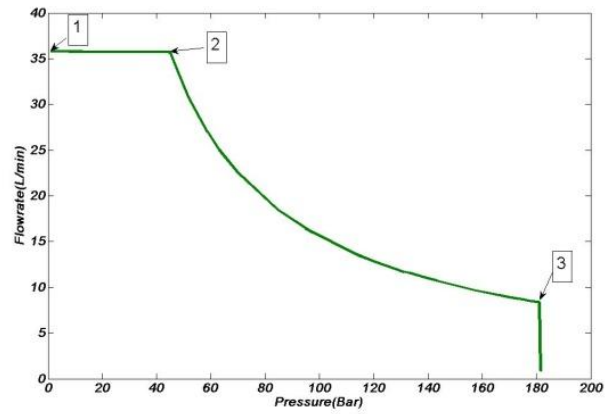

Fig. 1.(c) typical rocker arm working power controller diagram

Where $1=$ low pressure level, $2=$ the control commencement $\mathrm{P}_{\mathrm{cc}}, 3=\mathrm{P}_{\mathrm{co}}$ cut-off pressure

This paper deals with a smart design for a constant power controller for a swashplate piston pump. The study includes a theoretical part where a detailed nonlinear mathematical model is deduced and a computer simulation program is developed for the pump and its controller. Moreover, the steady state and transient response of the pump are mosured. The experimental results were used to validate the simulatiom program.

\section{PUMP CONSTRUCTION AND OPERATION}

\section{Operation at Low Pressure Level}

This operating mode is explained by Figs $2 \& 3$. When the pump delivery pressure Pp is very small, the active force $F_{P L}$ on the plunger (8) would be small, as well as its moment $F_{P L} l_{0}$ produced by the plunger (8) on the lever (9) around the fulcrum $O$. The moment $F_{p v} L_{v}$ acting on the lever due to the force of spring (19) pushes the lever to its extreme position, in the clockwise direction, and thus the spool (17) would in this case be at its lowest position inside the reducing valve. The control piston chamber would consequently be connected to the tank through the valve upper control gap, causing the pressure $P_{s p}$ to be zero. The two forces exerted on the piston (5) due to the delivery pressure $\left(\mathrm{P}_{\mathrm{p}} \mathrm{A}_{2}\right)$, and the spring (23), push the piston to the extreme right hand side position, where the control piston rests on the stroke limiter (6), and the pump geometric volume would be maximum value.

\section{Operation at Power Control Level (High Pressure Level)}

This operating mode is explained by Figs $2 \& 4$. As the delivery pressure slightly increases, the force $\mathrm{F}_{\mathrm{pl}}$ acting on the plunger increases. When the delivery pressure reaches a value, at which the moment $\mathrm{F}_{\mathrm{pl}} \mathrm{L}_{\mathrm{o}}$ becomes larger than the moment $\mathrm{F}_{\mathrm{pv}} \mathrm{L}_{\mathrm{v}}$, the lever (9) rotates around the axis $\mathrm{O}$ in the counter-clockwise direction. This forces the spool to move upwards until the increasing force in spring (19) stops it due to its compression. If in this position the upper control gap in the control valve remains open, the control piston chamber pressure $\mathrm{P}_{\mathrm{sp}}$ maintains its zero value, and the piston remains resting on the stroke limiter. If the delivery pressure rises again, the spool moves further upwards. The delivery pressure at which the spool closes both the upper and lower control gaps in the valve is called $\mathrm{p}_{\mathrm{o}}$. At this pressure, the control piston remains resting on the stroke limiter (6). Where $\mathrm{k}_{\mathrm{v}}$ is the stiffness of the pressure reducing valve spring (6), $\mathrm{X}_{\text {pro }}$ is its initial compression, and $\mathrm{u}$ is the upper control gap maximum opening which equals the spool displacement under this condition. 


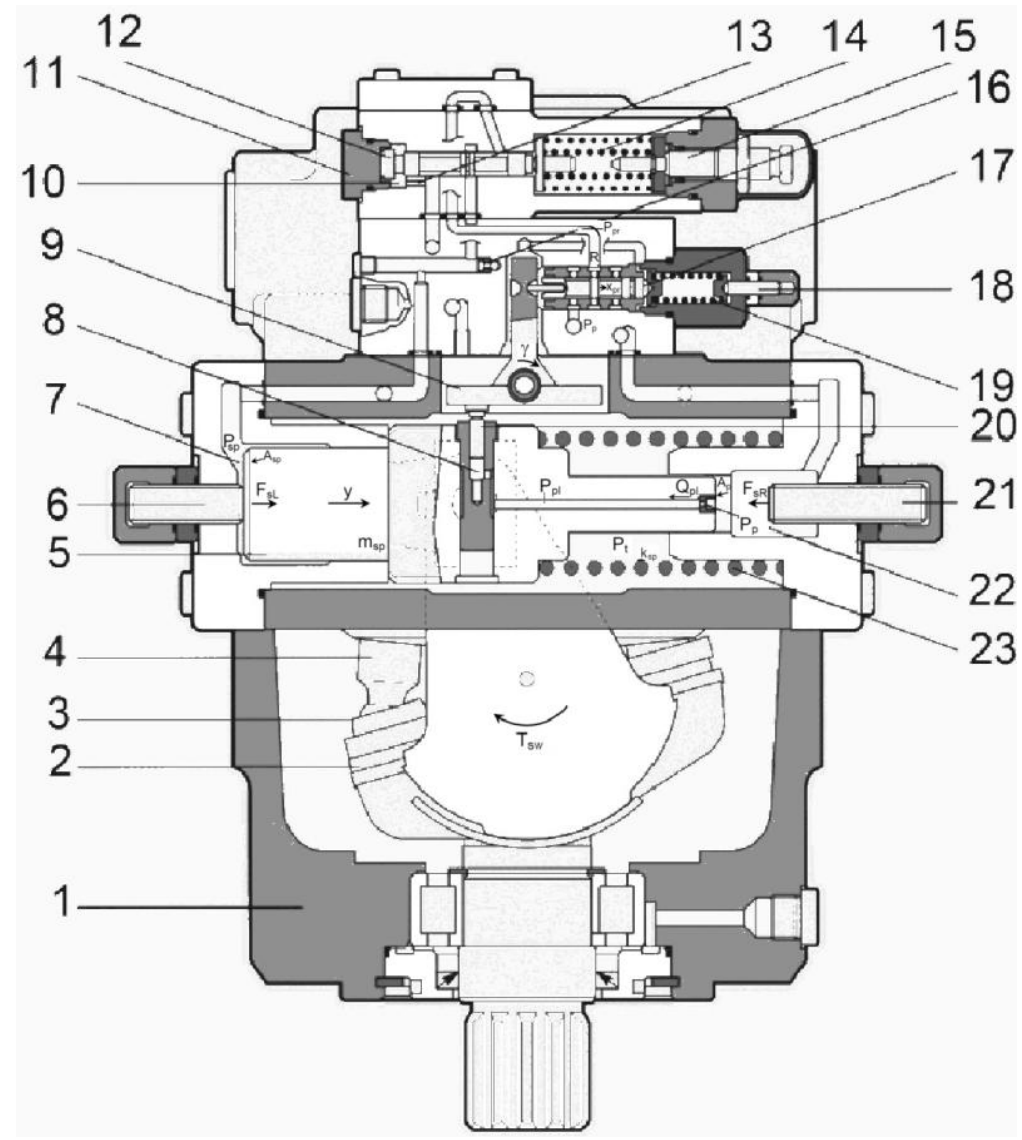

1. Housing, 2. Swash plate, 3.Slipper pad, 4. Pump pistons, 5. Servo-piston, 6.Left servo-piston seat (maximum displacement limiter), 7. Servo-piston chamber, 8. Plunger chamber, 9. Rocker arm, 10. Cut-off valve chamber, 11. Left seat of the cut-off valve spool, 12. Cut-off valve spool, 13. Cut-off valve damping orifice. 14. Cut-off valves springs, 15. Cut-off valve springs pre-compression adjusting screw (Setting of the cut-off pressure). 16. Damping orifice, 17. Pressure reducing valve spool, 18. Pressure reducing valve spring pre-compression setting screw (Setting of the control commencement pressure), 19. Pressure reducing valve springs, 20. Plunger, 21. Right servo-piston seat (Minimum displacement limiter, 22. Plunger chamber damping orifice, 23. Servo-piston spring.

Fig. 2 Schematic of the studied pump

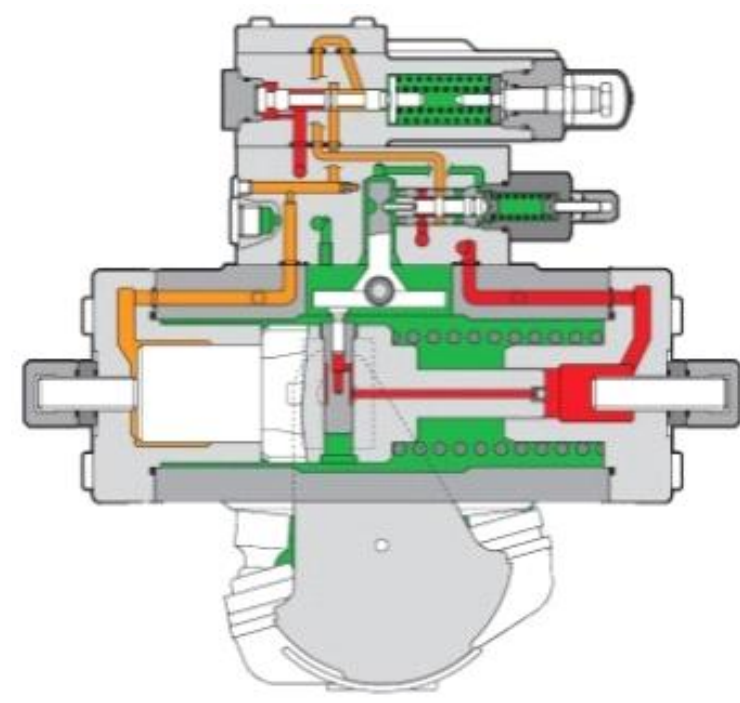

Fig. 3 Operation at low pressure

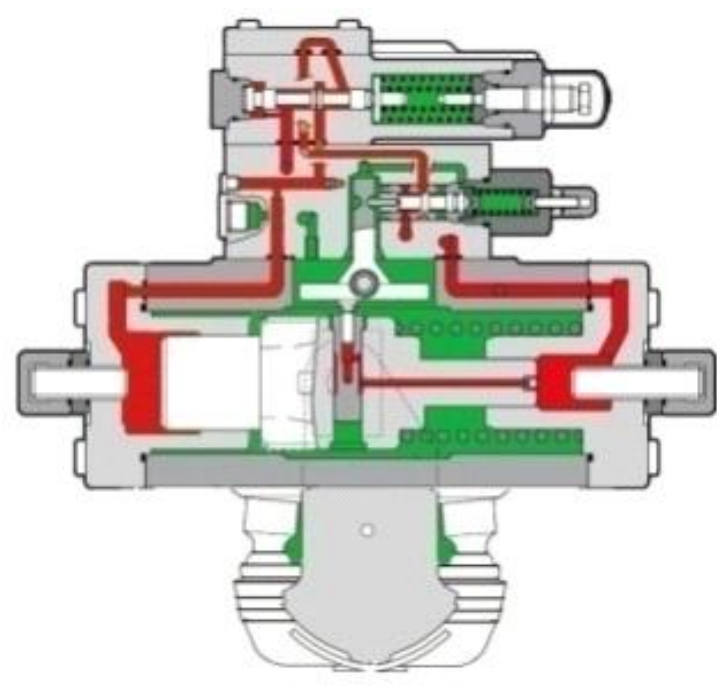

Fig. 4 Operation at High pressure

\section{Operation at Cut-Off Pressure}

When the delivery pressure exceeds $\mathrm{P}_{\mathrm{o}}$, the force $\mathrm{F}_{\mathrm{pl}}$ increases and its moment about $\mathrm{O}$ exceeds that of the spring force around the same point. In this instant, the lever rotates an extra angle in the counter-clockwise direction causing the spool to move upwards. Because of 
the spool displacement, the control piston chamber is connected to the pump delivery line through the lower control gap, which is now open, causing the pressure $\mathrm{P}_{\mathrm{sp}}$ to build up. When $\mathrm{P}_{\mathrm{sp}}$ reaches the value at which the force $\mathrm{P}_{\mathrm{sp}} \mathrm{A}_{1}$ exceeds the sum of the two forces $\mathrm{P}_{\mathrm{p}} \mathrm{A}_{2}$ and $\mathrm{k}_{\mathrm{sp}}\left(\mathrm{y}+\mathrm{y}_{\mathrm{o}}\right)$, then the piston (5) starts to move to the left causing a decrease in the pump geometric volume. When the control piston and, accordingly, the plunger (20) move to the left, the moment of the force $\mathrm{Fpl}$ around $\mathrm{O}$ decreases. This causes the lever to rotate about $\mathrm{O}$ but in the opposite direction, i.e. in the clockwise direction, forcing the spool to move downwards. The above conditions prevail until the spool reaches the position at which both the upper and lower control gaps are closed again. The control piston stops after traveling a displacement y to a new equilibrium position at this instant.

\section{MATHEMATICAL MODEL}

\section{Motion of the servo-piston}

The pressure forces, the spring force, the viscous friction force, the swash plate torque, the seat reaction forces and its inertia force, as shown in Fig.5 govern the servo-piston motion. Its motion is described mathematically by the following equation.

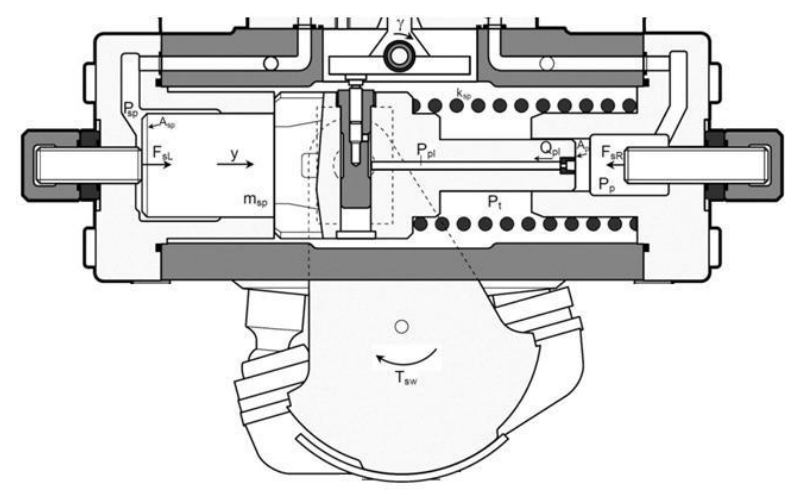

Fig. 5 Schematic of servopiston

$$
P_{s p} A_{s p}-P_{\mathrm{p}} A_{p}-F_{s R}+F_{s L}+F_{s w}=m_{s p} \frac{\mathrm{d}^{2} y}{\mathrm{dt}^{2}}+f_{s p} \frac{\mathrm{d} y}{\mathrm{dt}}+k_{s p}\left(y+y_{o}\right)
$$

Where

$$
F_{s w}=T_{s w} / r_{s}
$$

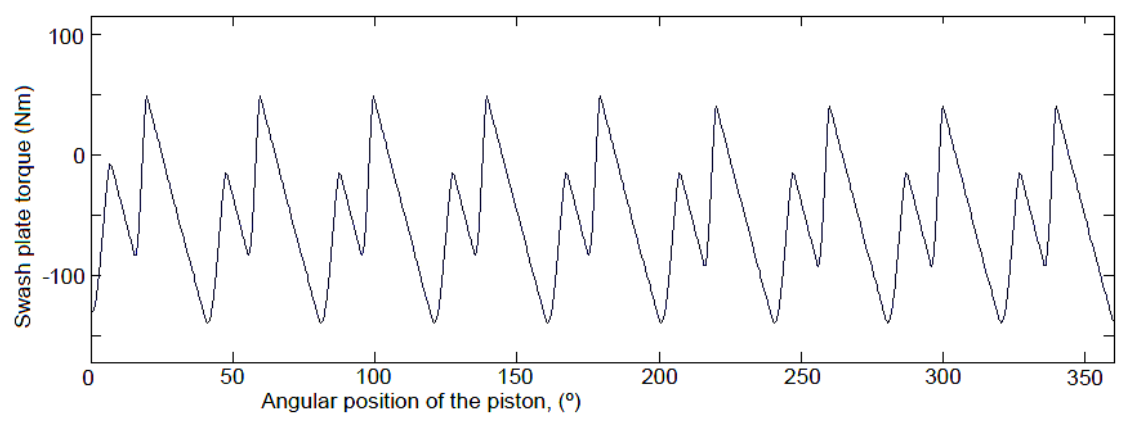

Fig. 6 SwashplateTorque_vs_theta [5]

The servo-piston displacement is limited mechanically in both directions. When reaching one of its seats, a seat reaction force takes place due to the action of the seat stiffness and structural damping of the seat material. These two effects are introduced by the equivalent seat stiffness $\mathrm{k}_{\mathrm{es}}$ and damping coefficient $\mathrm{R}_{\mathrm{es}}$. The extreme left position of the servo-piston is taken as the reference position, $\mathrm{y}=0$. The maximum servo-piston displacement is preset by the left limit adjusting screw (6), Fig.5. This is the maximum allowable displacement, $\mathrm{y}_{\mathrm{m}}$, at which, the swash plate angle and pump displacement are zero. The left seat reaction force is given by the following equation.

$$
F_{s L}=\left\{\begin{array}{cc}
0 & y>0 \\
k_{e s}|y|-R_{e s} \frac{d y}{d t} & y<0
\end{array}\right.
$$


The maximum servo-piston displacement is pre-set by the right limiting screw (21)as in Fig.1. The maximum servo-piston displacement determines the minimum swash plate angle and consequently the minimum pump flow rate. The right seat reaction force is given as follows.

$$
F_{s R}=\left\{\begin{array}{cc}
0 & \left(y-y_{m a}\right)<0 \\
k_{e s}\left|y-y_{m a}\right|+R_{e s} \frac{d y}{d t} & \left(y-y_{m a}\right)>0
\end{array}\right.
$$

Fig. 7 Transient response of servopiston displacement to step input servo-piston chamber pressure for $10 \mathrm{MPa}$ pump exit pressure and unloaded swash plate.

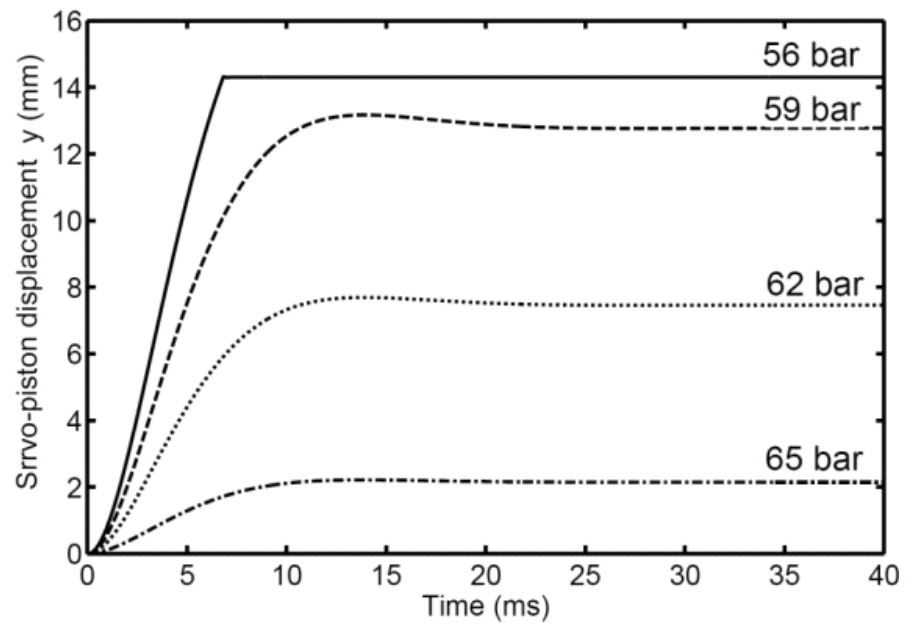

The dynamic behavior of the servo-piston is described mathematically by equations 1 thru 4 . These equations were used calculate the transient response of the servo-piston by developing a Simulink program. The response was calculated for step input servo-piston chamber pressure, $\mathrm{P}_{\mathrm{sp}}$, of different magnitudes. The calculations were carried out for unloaded swash plate and for constant pump exit pressure of $10 \mathrm{MPa}$. The calculated transient response, Fig.7, shows clearly the effect of end position limiters. It showed a settling time within $10 \mathrm{~ms}$ and an overshoot within $3 \%$.

\section{Rocker arm dynamics}

The rocker arm rotates under the action of the torque due to plunger pressure force, the torque due to the pressure reducer spring force, the viscous friction torque and its maximum displacement limiters. These displacement limiters limit the rocker arm rotational angle to \pm 0.083rad. The following equation describes the rocker arm motion.

Fig. 8 Schematic of the rocker arm and pressure reducing valve

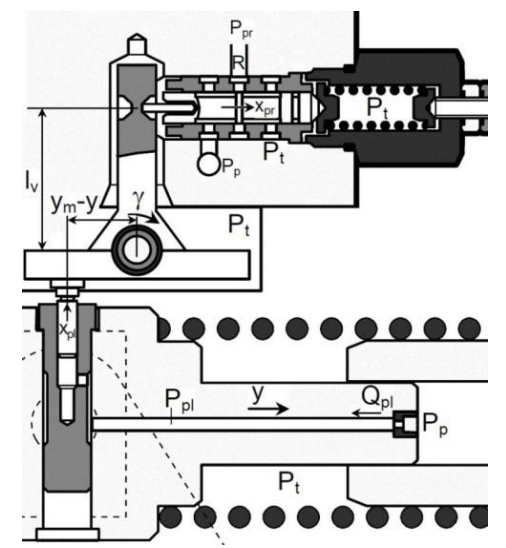

$$
\begin{aligned}
& P_{p l} A_{p l}\left(y_{m}-y\right)+\left(F_{r L}-F_{r R}\right) l_{r s}=J \frac{d^{2} \gamma}{d t^{2}}+f_{r a} \frac{d \gamma}{d t} \\
& +k_{p r}\left(x_{p r o}+x_{p r}\right) l_{v}
\end{aligned}
$$

The seat reaction forces limiting the rocker arm displacement are: 


$$
\begin{gathered}
F_{r L}=\left\{\begin{array}{cl}
0 & \left(\gamma-\gamma_{L}\right)>0 \\
-l_{r s} k_{r s}\left[\tan (\gamma)-\tan \left(\gamma_{L}\right)\right]-l_{r s} f_{s r a} \frac{d \gamma}{d t} \quad\left(\gamma-\gamma_{L}\right)<0
\end{array}\right. \\
F_{r R}=\left\{\begin{array}{cl}
0 & \left(\gamma-\gamma_{L}\right)<0 \\
l_{r s} k_{r s}\left[\tan (\gamma)-\tan \left(\gamma_{L}\right)\right]+l_{r s} f_{r s} \frac{d \gamma}{d t} & \left(\gamma-\gamma_{L}\right)>0
\end{array}\right.
\end{gathered}
$$

The spool of the plungers directly attached to the rocker arm and its displacement is:

$$
x_{p l L}=\left(y_{m}-y\right) \tan (\gamma)
$$

The spool of the pressure reducer is directly attached to the rocker arm and its displacement is

$$
x_{p r}=l_{r s} \tan (\gamma)
$$

The transient response of the rocker arm rotational angle to step increase plunger pressure, was calculated based on Eqs. 5 thru 8, using the SIMULINK program. The calculations were carried out for zero servo-piston displacement, Fig.9. The rocker arm response showed $3.2 \%$ maximum overshoot and $15 \mathrm{~ms}$ settling time, for $\mathrm{P}_{\mathrm{pl}}=40$ bar.

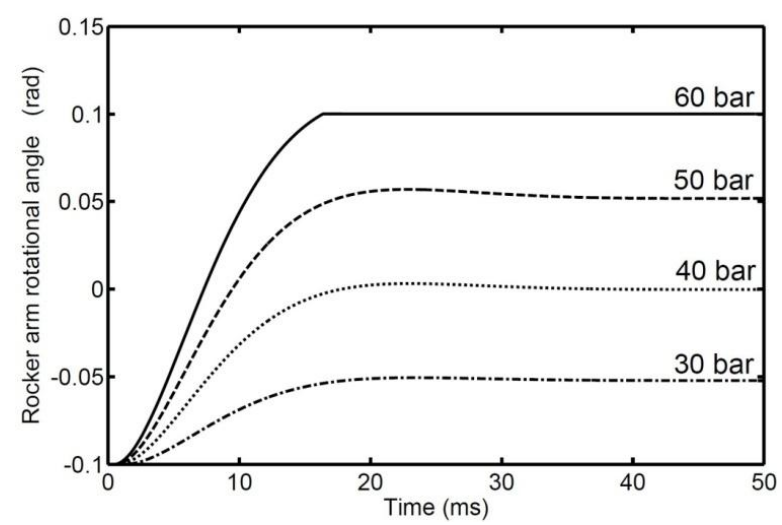

Fig.9 Transient response of rocker arm to step plunger chamber pressure increase

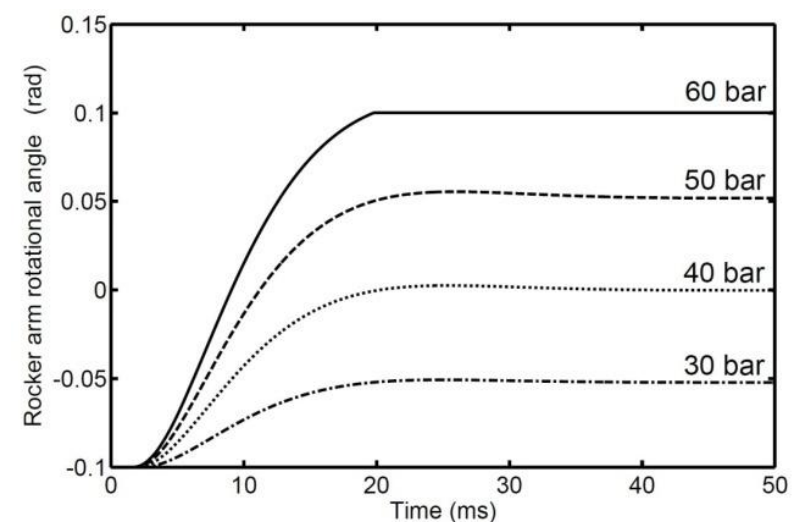

Fig. 10 Transient response of rocker arm to step pump exit pressure increase

\section{Fluid pressure in the plunger chamber}

The pressure in the plunger chamber is calculated by applying the continuity equation, considering the flow rate through the damping orifice, the plunger motion and oil compressibility. The following is the continuity equation applied to the plunger chamber.

$$
Q_{p l}-A_{p l} \frac{d x_{p l}}{d t}=\frac{V_{p l o}+A_{p l} x_{p l}}{B} \frac{d P_{p l}}{d t}
$$

The damping orifice connects the exit pressure chamber to the plunger chamber. It acts as a damping, energy dissipating element. The flow rate through this orifice is:

$$
Q_{p l}=C_{D} A_{o p l} \sqrt{2\left(P_{p}-P_{p l}\right) / \rho}
$$

The transient response of the rocker arm rotational angle to step increase pump exit pressure, was calculated based on Eq.1.5 thru 1.10, using the SIMULINK program. The calculations were carried out considering zero servo-piston displacement, Fig.10. The rocker arm response showed $2.5 \%$ maximum overshoot and $17.4 \mathrm{~ms}$ settling time. Moreover, a slight delay of response and slight reduction of overshoot are observed, due to the effect of damping orifice. 


\section{Pressure reducing valve flow rates and pressure}

The pressure-reducing valve connects its exit port $(R)$ with the high-pressure line (of pressure $P_{p}$ ) and the return line (of pressure $\mathrm{P}_{\mathrm{t}}$ ). Its exit pressure is determined by the continuity of flow in its exit chamber. The fluid flows through circular holes, controlled by the mid land of the spool, Fig.11. The spool clears out a part of circular area to connect the different ports, Fig.12. Generally, the area cleared due to the spool displacement, $\mathrm{x}$, can be calculated as follows.

Fig. 11 Pressure reducer flow rates, pressures and areas

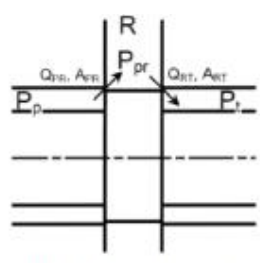

Fluid flow through the pressure reducer

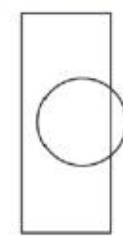

$\mathrm{X}_{\mathrm{pr}}<0$, $A_{R T}$ Opened

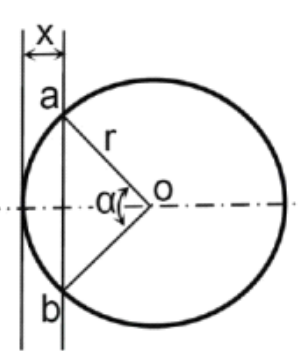

$\mathrm{x}<\mathrm{r}$

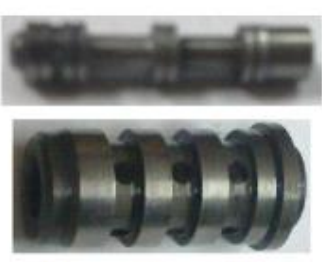

Valve spool and sleeve

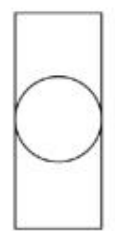

$\mathrm{X}_{\mathrm{pr}}=0$,

Zero lapping

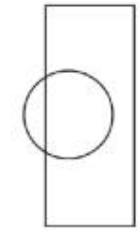

$\mathrm{Xpr}>0$,

APR Opened

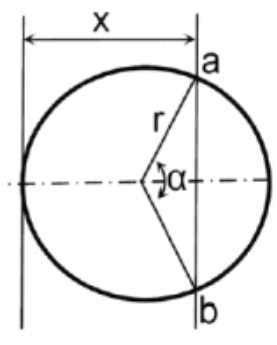

$\mathrm{x}>\mathrm{r}$

$$
\text { For } r<x<2 r\left\{\begin{array}{c}
\alpha=2 \cos ^{-1}\left(\frac{r-x}{r}\right) \\
\overline{a b}=2 r \sin (\alpha / 2) \\
A_{t}=0.5 r^{2} \alpha-0.5 \overline{a b}(r-x) \\
A_{t}=\pi r^{2}-\left\{0.5 r^{2} \alpha-0.5 \overline{a b}(x-r)\right\} \\
\overline{a b}=2 r \sin (\alpha / 2) \\
\text { For } \mathrm{x}>2 \mathrm{r} ; \quad A_{t}=\pi r^{2}\left(\frac{x-r}{r}\right)
\end{array}\right.
$$

The throttle area, $A_{t}$, is limited by the circle area: $\left(\pi r^{2}\right)$. The opened area was calculated in non-dimensional form, relative to the area $\left(\pi r^{2}\right)$ and plotted in Fig.13. 


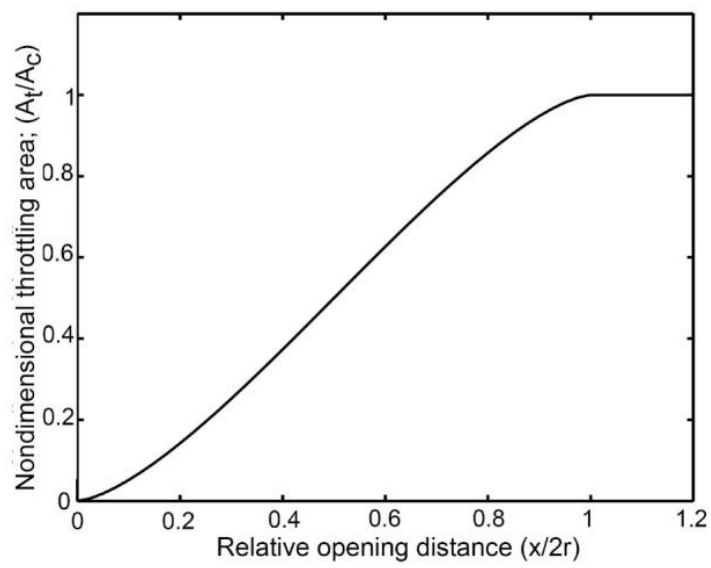

Fig. 13 Non-dimensional plot of the opened area of the circular hole.

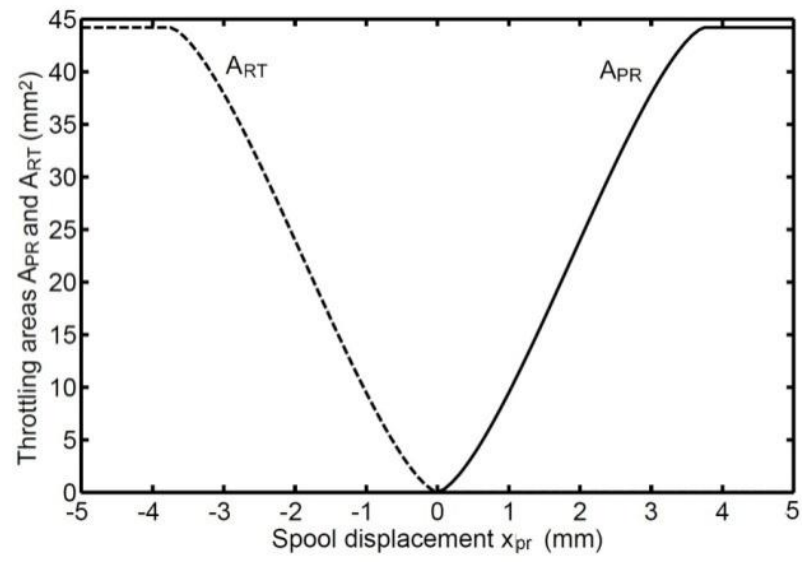

Fig. 14 Throttling areas of the pressure reducer with the spool displacement

The throttling areas of the pressure reducer, Fig.14, are calculated by the following expressions [1].

The throttling areas $A_{P R}$ and $A_{R T}$ were calculated using the above-mentioned equations. These equations did not consider the spool radial clearance. Therefore, they are limited to a minimum value equal to the radial clearance throttling area. The calculation results are given in Fig.14. During the pump controller operation, the pressure reducer spool displacement is limited to $\pm 4 \mathrm{~mm}$ and the throttle areas vary within 0 to $44.1 \mathrm{~mm}^{2}$

$$
\begin{aligned}
& A_{P R}=\left\{\begin{array}{cc}
0 & x_{p r}<0 \\
r_{p r}^{2} \cos ^{-1}\left(\frac{r_{p r}-x_{p r}}{r_{p r}}\right)-r_{p r}\left(r_{p r}-x_{p r}\right)\left(2 x_{p r}-x_{p r}^{2} / r_{p r}\right) & 0<x_{p r}<r_{p r} \\
\pi r_{p r}^{2}-\left\{r_{p r}^{2} \cos ^{-1}\left(\frac{x_{p r}-r_{p r}}{r_{p r}}\right)-r_{p r}\left(x_{p r}-r_{p r}\right)\left(2 x_{p r}-x_{p r}^{2} / r_{p r}\right)\right\} & r_{p r}<x_{p r}<2 r_{p r} \\
\pi r_{p r}^{2} & x_{p r}>2 r_{p r}
\end{array}\right. \\
& A_{R T}=\left\{\begin{array}{cc}
0 & x_{p r}>0 \\
r_{p r}^{2} \cos ^{-1}\left(\frac{\left.r_{p r}+x_{p r}\right)}{r_{p r}}\right)-r_{p r}\left(r_{p r}+x_{p r}\right)\left(-2 x_{p r}-x_{p r}^{2} / r_{p r}\right) & 0<-x_{p r}<r_{p r} \\
\pi r_{p r}^{2}-\left\{r_{p r}^{2} \cos ^{-1}\left(\frac{-x_{p r}-r_{p r}}{r_{p r}}\right)-r_{p r}\left(-x_{p r}+r_{p r}\right)\left(-2 x_{p r}-x_{p r}^{2} / r_{p r}\right)\right\} & r_{p r}<-x_{p r}<2 r_{p r} \\
\pi r_{p r}^{2} & -x_{p r}>2 r_{p r}
\end{array}\right.
\end{aligned}
$$

The flow rates through the pressure reducer are given by the following equations.

$$
\begin{gathered}
Q_{P R}=C_{D} A_{p r} \sqrt{2\left(P_{p}-P_{p r}\right) / \rho} \\
Q_{R T}=C_{D} A_{R T} \sqrt{2\left(P_{p r}-P_{t}\right) / \rho}
\end{gathered}
$$

The pressure in the exit line is calculated applying the continuity equation to this line. 


$$
Q_{p r}-Q_{R T}-Q_{R}=\frac{V_{p r}}{B} \frac{d P_{p r}}{d t}
$$

The reduced pressure variation with the pressure reducer spool valve displacement was calculated, based on Eqs 17 to 19.The calculations were carried out considering 100 bar pump exit pressure and zero exit flow rate. The results are shown in Fig.15. These results show that the effective spool displacement is within $\pm 0.05 \mathrm{~mm}$. The reduced pressure is practically constant outside of this range.

Fig. 15 Variation of the reduced pressure at 100 bar pump pressure

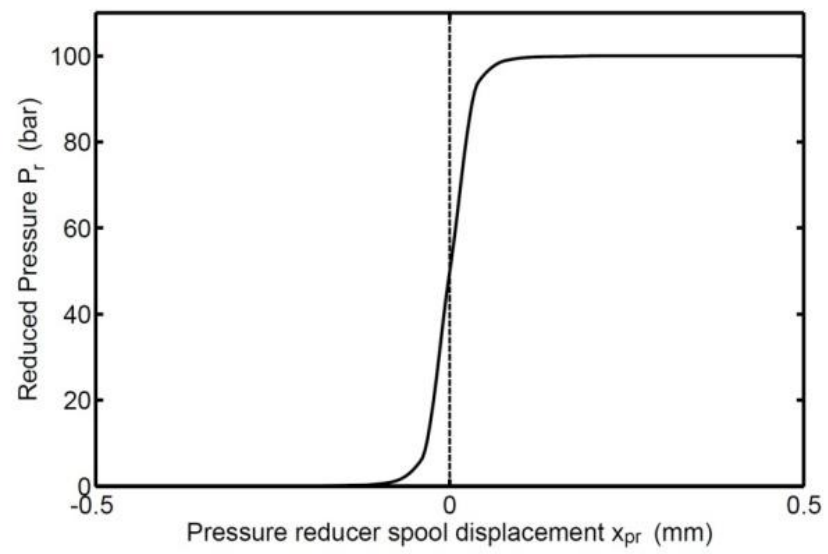

\section{Pump with cut-off valve}

Flow rates through the pressure-reducing valve will be

$$
\begin{aligned}
& Q_{p r o}=C_{D} A_{p r o} \sqrt{2\left(P_{p}-P_{p r}\right) / \rho} \\
& Q_{p r i}=C_{D} A_{p r i} \sqrt{2\left(P_{p r}-P_{t}\right) / \rho}
\end{aligned}
$$

\section{Equation of motion of cut-off valve spool}

The cut-off valve spool moves under the action of the pressure force, seat reaction force, its spring force and its viscous damping force. The following is its equation of motion.

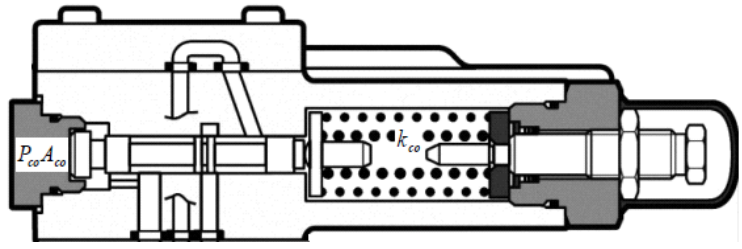

Fig. 16 Schematic cut-off valve

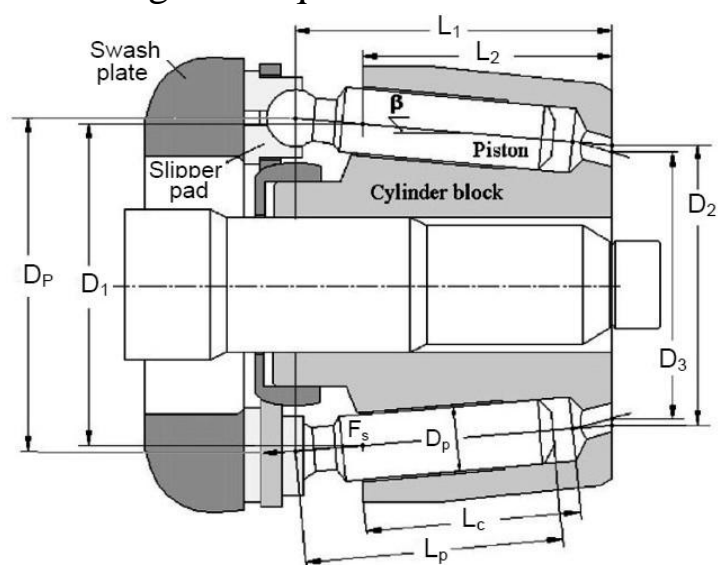

Fig. 17 Pumping mechanism

$$
\begin{gathered}
P_{c o} A_{c o}-F_{c o L}=m_{c o} \frac{d^{2} x_{c o}}{d t^{2}}+f_{c o} \frac{d x_{c o}}{d t}+k_{c o}\left(x_{c o}+x_{c o o}\right) \\
F_{c o L}=\left\{\begin{array}{cc}
0 & x_{c o}>0 \\
k_{e s}\left|x_{c o}\right|+R_{e s} \frac{d x_{c o}}{d t} & x_{c o}<0
\end{array}\right.
\end{gathered}
$$

\section{Cut-off valve throttling areas}




$$
\begin{aligned}
& \left.\begin{array}{l}
A_{c o o}=\omega c \\
A_{c o i}=\omega \sqrt{\left(x_{c o}-x_{c o i}\right)^{2}+c^{2}}
\end{array}\right\} \quad \text { For } x_{c o} \geq x_{c o i} . \\
& \left.\begin{array}{l}
A_{c o o}=\omega \sqrt{\left(x_{c o i}-x_{c o}\right)^{2}+c^{2}} \\
A_{c o i}=\omega c
\end{array}\right\} \quad \text { For } x_{c o} \leq x_{c o i}
\end{aligned}
$$

\section{Flow rate through the cut-off valve-damping orifice}

The damping orifice connects the exit pressure chamber to the cut-off valve left chamber. It acts as a damping element. The flow rate through this orifice is:

$$
Q_{c o}=C_{D} A_{c o d} \sqrt{2\left(P_{p}-P_{c o}\right) / \rho}
$$

Continuity equation applied to the cut-off valve left chamber

$$
Q_{c o}-A_{c o} \frac{d x_{c o}}{d t}=\frac{V_{c o o}+A_{c o} x_{c o}}{B} \frac{d P_{c o}}{d t}
$$

Flow rates through the cut-off valve

$$
\begin{gathered}
Q_{\text {coo }}=C_{D} A_{c o o} \sqrt{2\left(P_{p}-P_{s p}\right) / \rho} \\
Q_{c o i}=C_{D} A_{c o i} \sqrt{2\left(P_{p r}-P_{s p}\right) / \rho}
\end{gathered}
$$

In this study, a throttle valve of sharp edged restriction loads the pump. The pump exit pressure, $\mathrm{P}_{\mathrm{p}}$, is adjusted by setting-up the throttle area $\mathrm{A}_{\mathrm{th}}$. The flow rate through the throttle valve is:

$$
Q_{t h}=C_{D} A_{t h} \sqrt{\frac{2}{\rho}\left(P_{p}-P_{t}\right)}
$$

The pressure at the pump exit line can be calculating by applying the continuity equation to the pump exit line.

$$
Q_{p}-Q_{t h r}=\frac{B}{V_{p e}} \frac{d P_{p}}{d t}
$$

In this case, the incorporated pressure cut-off valve imposes the limitation of pump exit pressure. However, in the practical applications a pressure relief valve should be installed at the pump exit line. This counts for possible defects in the pump controller elements.

\section{VALIDATION OF THE SIMULATION PROGRAM}

The developed simulation program was validated by comparing simulation and experimental results. Figure 18 shows the hydraulic circuit of the test bed used to measure the steady state abd trabsient response of the pump.

\section{Validation of Simulation Program in the Steady State}

The steady state pump flow rate was measured and calculated busing the simulation prohrams for different maximum and command commencement pressures. The simulation and experimentsl results are plotted in Fig. 19 (a) and (b). The study of this figure shows that the simulation and experimental results are in good agreement, which validates the simulation program in the steady state. 


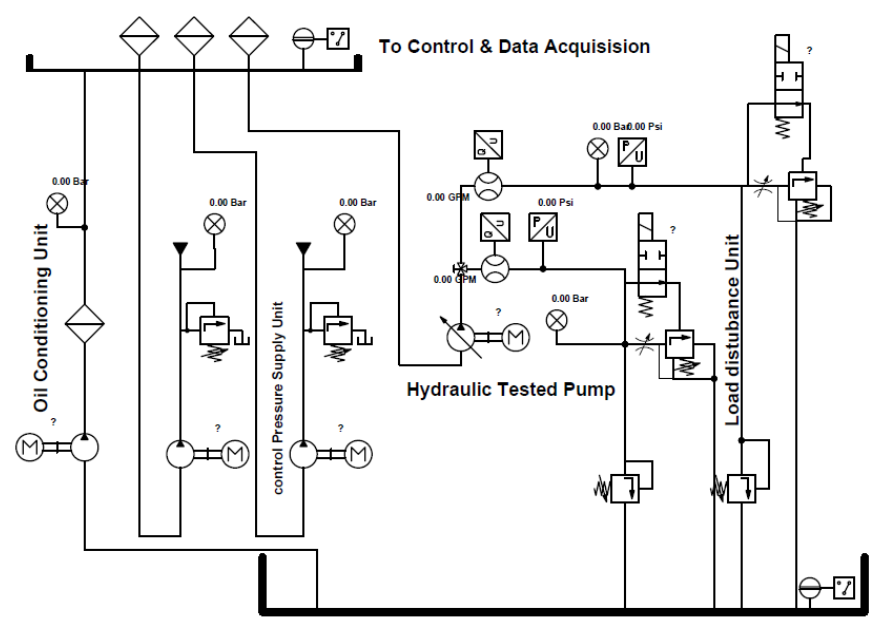

Fig. 18 Hydraulic circuit of the test bed

\section{Validation of Simulation Program in the transient conditions}

The transient response of the pump to step closure of the pump exit line was measured. A high response 4/2 directional control valve was used for this purpose. The pump response at the same operating conditions was calculated using the simulation program. The simulation and experimentsl results are plotted in Fig. 20. The study of this figure shows that the simulation and experimental results are in good agreement, which validates the simulation program in the transient mode of operation.

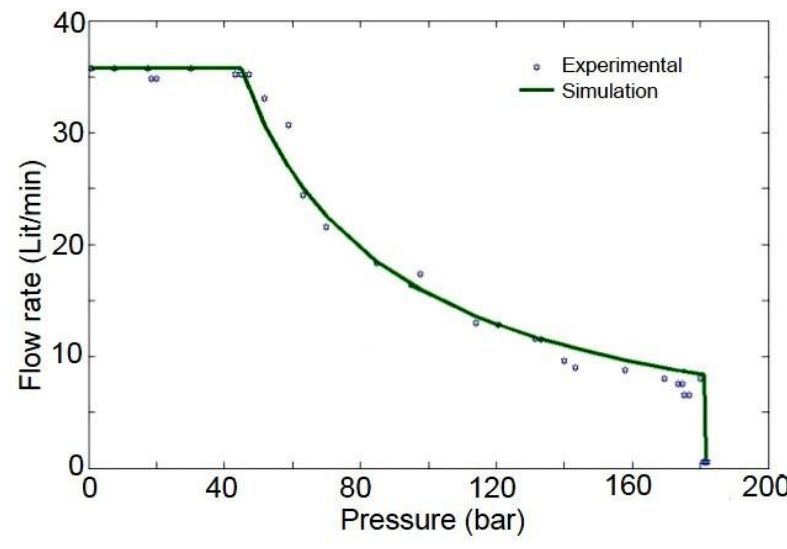

(a) $\mathrm{P}_{\max }=36$ bar, $\mathrm{P}_{\mathrm{cc}}=45$ bar $\& \mathrm{P}_{\mathrm{co}}=180$ bar

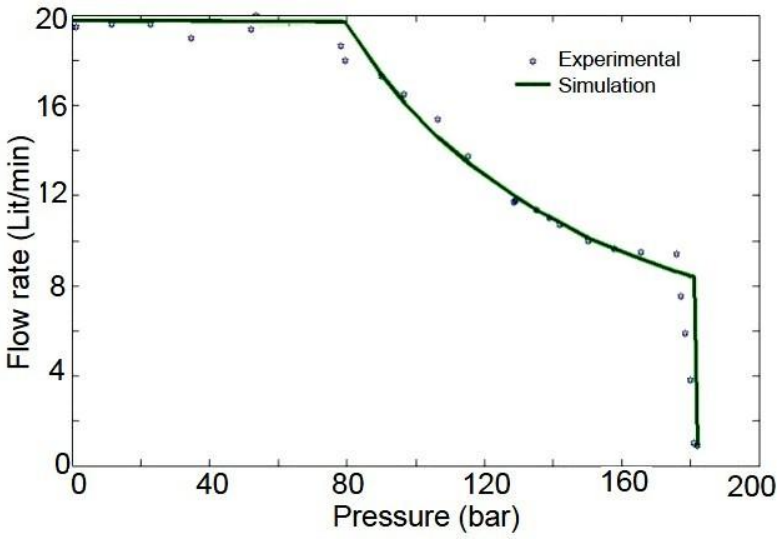

(b) $\mathrm{P}_{\max }=19$ bar, $\mathrm{P}_{\mathrm{cc}}=79.4$ bar $\& \mathrm{P}_{\mathrm{co}}=180$ bar

Fig. 19 Experimental and simulation results of pump steady state flow characteristics

Fig. 20 Experimental and simulation results of the pump transient response

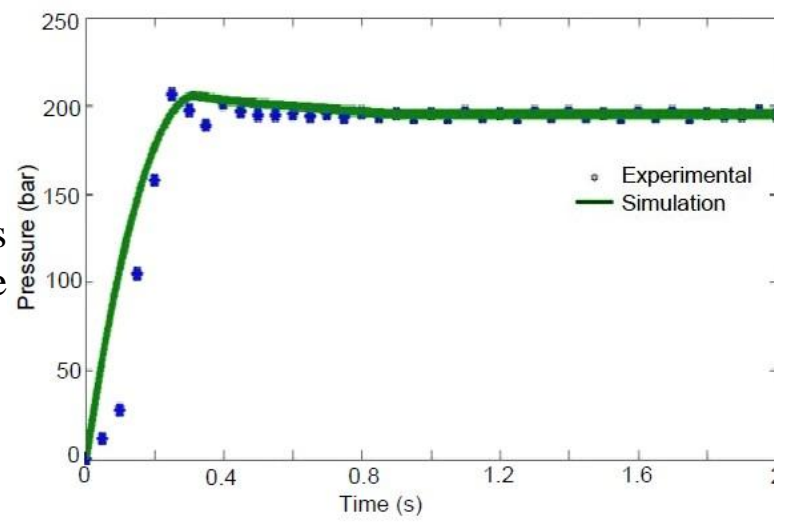




\section{Parametric Study}

In the previous sections, the Power controlled pump model was established and validated. The validation shows great trust in the established model structure. The effect of changing the operating condition on the Power controlled pump performance could be studied using the validated model. In this section the Power controlled pump performance and dynamic behavior are studied using the simulation program.

\section{Effect of setting of pump control commencement pressure}

\section{Description of operation}

Pressure reducing valve spring pre-compression (see fig. 21) setting screw used to control commencement pressure tightening valve-reducing limiter or loosen it

\section{Simulation results}

The Power controlled pump performance is shown at three pump Xpro setting. The performance is shown when the pump is subjected to the loading pressure from the initial tank pressure to the selected value (by changing the variable throttle area to the corresponding value) in steady state. A comparison between each parameter performance at these conditions is shown graphically.

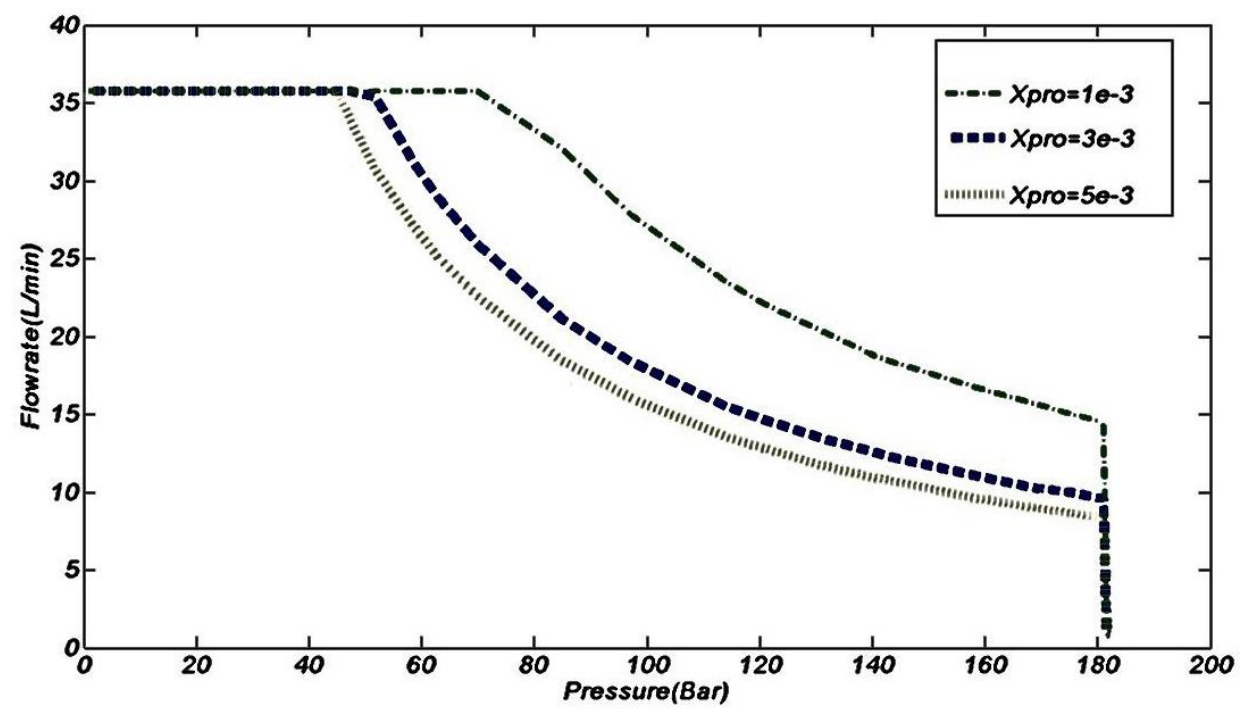

Fig. 21 XPro change effect

When raising the Xpro (which means tightening valve reducing limiter) pump control commencement pressure rise. The power controlled (parabola) regime is shifted upward which means more power needed to drive the pump.

\section{Effect of setting of pump stroke limiter displacement}

\section{Description of operation}

Left servo-piston seat used to control maximum displacement limiter (see fig. 22) setting screw to the appropriate maximum value by tightening or loosen it

\section{Simulation results}

The Power controlled pump performance is shown at three pump yLL left stroke limiter setting. The performance is shown when the pump is subjected to the loading pressure from the initial tank pressure to the selected value (by changing the variable throttle area to the 
corresponding value) in steady state. A comparison between each parameter performance at these conditions is shown graphically

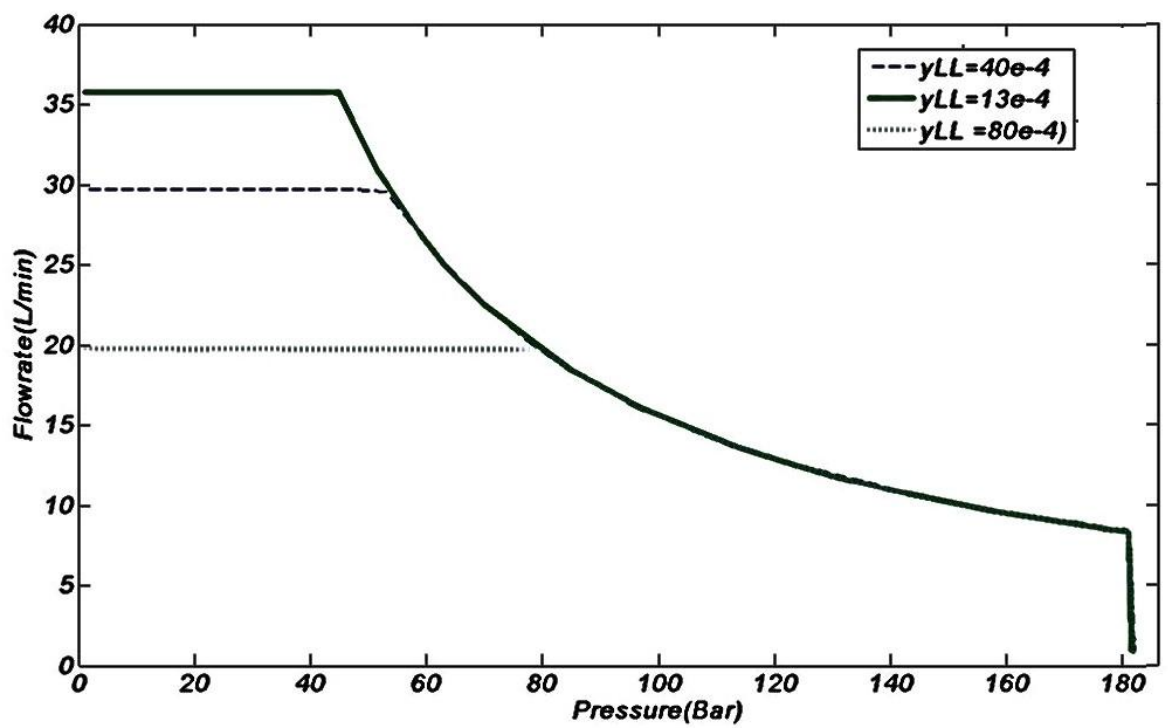

Fig. 22 yLL effect(yLL=13e-4, yLL=40e-4, yLL=80e-4)

When using mechanism of rising yLL which means tightening swash plate positioning piston left stroke limiter)the Power controlled (parabola)regime is shifted downward which means less power needed to drive the pump.

I.e: trying to do the same for the right stroke limiter limited the ability of power control to function well either theoretically or experimentally.

\section{Effect of setting pump Cut-off pressure}

\section{Description of operation}

Cut-off valve springs pre-compression adjusting screw (see fig. 23) used to control setting of the cut-off pressure by tightening or loosen it.

\section{Simulation results}

The Power controlled pump performance is shown at three pump Xcoo(Initial Cut-off valve springs pre-compression spring) pump setting. The performance is shown when the pump is subjected to the loading pressure from the initial tank pressure to the selected value (by changing the variable throttle area to the corresponding value) in steady state. A comparison between each parameter performance at these conditions is shown graphically.

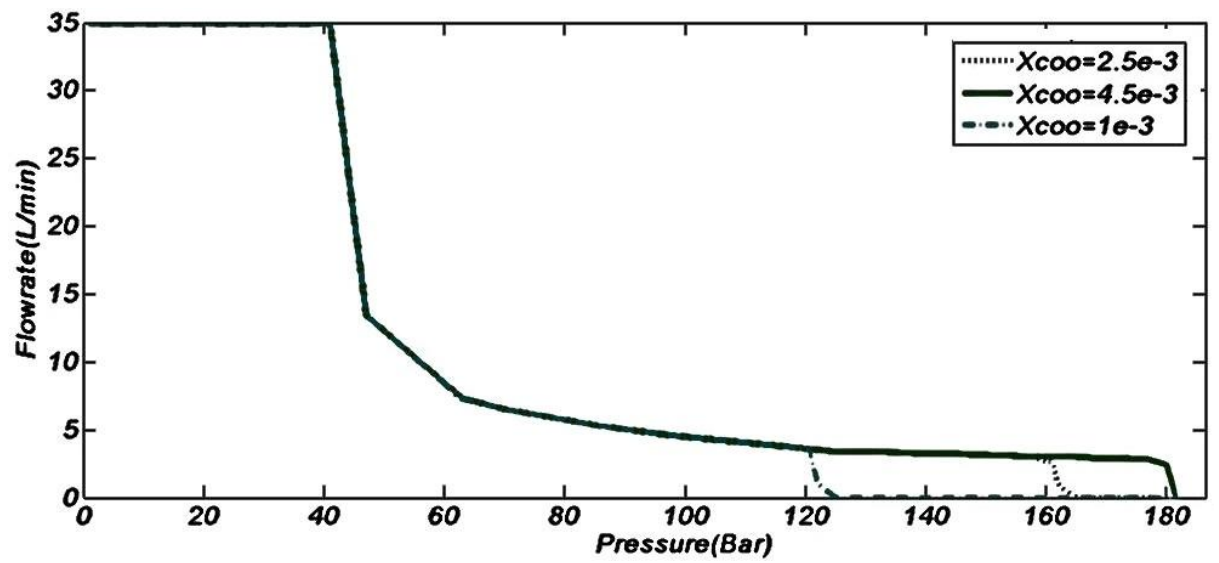

Fig.23 Cut-off spring initial compression(yLL=13e-4) 
This parameter is used to control the cut off pressure, which means the operating pressure at which positioning piston went to its end stroke which means the least flow. It can be seen by raising Xcoo Initial compression of pressure reducer spring, the cut-off pressure will rise.

\section{CONCLUSIONS}

This paper is dedicated to investigate the performance of a swashplate axial piston pump, equipped with a covstant power controller. The study included a development of a nonlinear mathematical model and a computer simulation program. The transient response and steady state characteristics of the pump were evaluated experimentslly, and the experimental results were used to validate the simulation program. The following conclusions could be reached:

- The pump controller produces, practicall, a hyperbolic pressure-flow rate relation over, which provides an essential economic advantage for this class of pumps.

- The swash plate torque oscillates around a negative mean value, producing a swash plate restoring torque.

- The attained simulation program is applicable for the further pump study, mainly; the pump cavitation characteristics, the possible impronment of pump behavior and improving the pump dynamic performance.

\section{REFERENCES}

[1] M Galal Rabie, Fluid Power Engineering, McGraw-Hill, NY, 2009.

[2] H. Kemph, Hydraulics, Basic Principles and Components, $3^{\text {rd }}$ Edition, Mannesmann Rexroth GmbH, Germany, May 2003

[3] O. GAD; M. GALAL RABIE and R. EL-TAHER,"Prediction and Improvement of Steady-State Performance of a Power Controlled Axial Piston Pump", ASME, Journal of Dyn. Sys., Meas., and Control, Sept. 2002, Vol. 124

[4] Mannesmann Rexroth, "Variable Displacement Pump A7VO," Data sheet No. RE 92203/03.92, Mannesmann Rexroth Gmbh, Germany, 1992, pp 1-20.

[5] M. Semeda,"Performance Investigation of the Swash Plate Axial Piston Pumps Having Conical Cylinder Block with Constant Power Regulation", MSc thesis, Faculty of Engineering, Cairo Univ., Egypt, 2012

[6] S.A. Kassem and M. Bahr, "Fuzzy Logic Control of Constant Power Regulated Swash Plate Axial Piston Pumps," in Proceedings of the International Mechanical Engineering Congress and Exposition, New York, 2001. 